\title{
Self-directed Learning Predicts Online Learning Engagement in Higher Education Mediated by Perceived Value of Knowing Learning Goals
}

\author{
Wei Sun ${ }^{1} \cdot$ Jon-Chao Hong ${ }^{2}$ Yan Dong ${ }^{1}$ Yue Huang ${ }^{3} \cdot$ Qian Fu $^{1} \mathbb{D}$
}

Accepted: 14 February 2022/Published online: 5 March 2022

(c) De La Salle University 2022

\begin{abstract}
Online education has made it possible to implement the "classes suspended but learning continues" policy during the COVID-19 outbreak. However, the intangible sense of the online educational setting requires self-directed learning (SDL) and may force students to know the goals of learning that may impact their engagement. To understand the effect, based on situated expectancy-value theory, this study considered SDL as attitude and approach and constructed a research model to explore the mediating power of perceived value of knowing learning goals (PVKLG) related to participants' online learning engagement during the COVID-19 lockdown. Data were collected from 497 higher education students in China. After the confirmatory factor analysis with structural equation modeling, the results reported that SDL
\end{abstract}

Qian Fu

fredqian@bnu.edu.cn

Wei Sun

bnusw0512@mail.bnu.edu.cn

Jon-Chao Hong

tcdahong@gmail.com

Yan Dong

yan.dong@bnu.edu.cn

Yue Huang

huangy@bupt.edu.cn

1 School of Educational Technology, Faculty of Education, Beijing Normal University, No. 19 XinJieKouWai St., HaiDian District, Beijing 100875, People's Republic of China

2 Department of Industrial Education, Institute for Research Excellence in Learning Sciences, National Taiwan Normal University, Taipei, Taiwan, ROC

3 School of E-learning, Beijing University of Posts and Telecommunications, Beijing, People's Republic of China attitude and approach positively predicted learning engagement mediated by PVKLG. The results suggest that only when students have a high level of PVKLG will they be able to regulate their learning process through the two types of SDL and enhance their engagement in online learning contexts during the COVID-19 lockdown.

Keywords Self-directed learning - Learning engagement · Learning goals $\cdot$ Perceived value $\cdot$ Online learning

\section{Introduction}

Online education has gained much attention and has been adopted by higher education institutions in recent years, especially during the outbreak of COVID-19. Online education has the potential to make learning processes more student-centered (Dwivedi et al., 2019). However, it has been reported that during COVID-19, students' online learning engagement in higher education has been low (Pengpai News, 2020). In this circumstance, online learning effects mainly depend on students' self-directed learning (SDL) (Zheng et al., 2020). Additionally, in online learning contexts, participants need to know the learning goals that influence them in order to regulate their learning (Zhu, 2021). However, few studies have looked at whether learning goals affect students' learning engagement if they know about them.

Students often ask "Why do I have to learn this?" (Schmidt et al., 2019), which indicates that the perceived usefulness of learning a subject is the main determinant of particular learning behaviors (Dweck, 1986). That is, attainment or utility value is related to the centrality of goals for learners' sense of identity (Eccles, 2009). Moreover, to elaborate on value theory, Eccles and Wigfield 
(2020) updated the expectancy-value theory (EVT) with social cognition and sociocultural perspectives, naming the revised version the Situated Expectancy-Value Theory (SEVT). SEVT stresses the impact that both the situation and the cultural background have on an individual's developing expectancy and value. Considering online learning during COVID-19, it is situated in an epidemic sociocultural condition, which makes it possible to carry out all teaching-related activities on the Internet. This situation presents an expectation of how online learners can benefit from online learning which requires their SDL (Beach, 2017; LaTour, \& Noel, 2021). Besides, students' expectancy and value beliefs about different types of situated learning are important predictors of the effort students make and their engagement in those situations (Wigfield et al., 2009). As COVID-19 has created a new situation of having students learn online, how the learning values as learning goals students expect that may relate to their online learning engagement is interested in this study.

Various domain-specific, cross-sectional studies have found that perceived task value and related expectancy of success are positively correlated with and interactively linked to students' achievement and to their academic choices (e.g., Guo et al., 2017; Seetee et al., 2021). However, how SDL influences the value perception of learning goals and reflects their online learning engagement has not been extensively studied during COVID-19; thus, the present study drew on SEVT to form a research model to explore students' SDL in predicting their learning goal value perception and learning engagement, particularly when using Zoom or Tencent Lecture Hall as the online learning platform.

\section{Literature Review}

\section{The Situated Expectancy-Value Theory}

EVT has been adopted in numerous studies to predict and explain students' task choices, their learning persistence, and their academic performance (Wigfield \& Eccles, 2000). Traditionally, EVT argued that students' expectancy of success and their subjective task value had a direct influence on their achievement choices, effort, persistence, and performance (Wigfield \& Eccles, 1992, 2000). EVT has been widely applied in different domains, including language learning (e.g., Seetee et al., 2021), science subjects (e.g., Guo et al., 2017), and mathematics (e.g., Fong et al., 2021). Those studies revealed that school and national curricula seem to offer students fewer choices and less autonomy in the highly competitive learning situation, which erodes students' expectancy to put in effort, especially in those subject domains in which they have learning difficulties (Loh, 2019). In line with the limitation of EVT to address the application of value theory, Eccles and Wigfield (2020) extended the classic expectancy-value model to SEVT. They discussed the central part of the model which focuses on how learners understand and interpret their performance and their perceived value of their activity participation in a particular situation.

In SEVT, Eccles and Wigfield (2020) stress the impacts that situations have on learners' developing expectancy and value and their relation to performance, choice, and engagement. Learners need to make decisions about what goals to study, in what order to study, how to study, how long to study, when to study, and when to terminate their study, but they may not always make effective choices; thus, there is a critical need to understand attitudes and processes behind learners' choices to ensure better learning engagement (Kirk-Johnson et al., 2019). Based on SEVT, the present study examined the direct relationships between the approach and attitude of SDL and perceived value of knowing learning goals (PVKLG), and PVKLG for predicting students' online learning engagement during COVID-19.

\section{Self-directed Learning Attitude and Approach}

Garrison (1997) stated that SDL is "an approach where learners are motivated to assume personal responsibility and collaborative control by self-monitoring and selfmanagement" (p. 18). Moreover, learning approaches are dynamic; they can change depending on context, which emphasizes the significance of the contextual situation (Dolmans et al., 2016). Caffarella (1993) illustrated SDL as an attitude toward self-initiated learning. Song and Hill (2007) highlighted SDL including learning approaches, personal attitude, and learning contexts as the effect of SDL in online environments. Accordingly, this study divided SDL into SDL attitude and approach, both of which affect learners' online learning behavior.

Previous research has shown that learners' learning attitudes and approaches impact their concentration while learning; moreover, learning attitudes and approaches are context dependent (Biggs et al., 2001). In line with the school lockdown situation of COVID-19, virtual learning has become socioculturally dependent (Eccles \& Wigfield, 2020), and the self-control of learners has become essential to success in online learning. Learners' attitude and approach toward learning will also have a great impact on the learning effects. Hence, the roles that students' different types of SDL play in their online learning during the pandemic were explored in this study. 


\section{Perceived Value of Knowing Learning Goals}

According to Seijts et al. (2013), “A learning goal frames the goal instructions in terms of knowledge or skill acquisition" (p. 196). In the educational context, the definition of perceived value emphasizes learners' trade-off choice (de Moura et al., 2021). Briefly, knowing learning goals can enable students to participate meaningfully in learning processes, which plausibly improves the perceived value of learning (Torshizi \& Bahraman, 2019), when students perceive that the value of knowing learning goals can motivate them to achieve the goals (Chang et al., 2018). Thus, this study considered PVKLG as an important factor for improving students' performance in online learning.

In educational programs which design learning goals with a transformative aim of information processing (Stetsenko, 2017), as Bloom's Taxonomy of educational objectives, the model of human information processing is implicited (Arievitch, 2020). Moreover, learning goals differ across tasks in different learning situations (Hein et al., 2019). Although previous studies have explored learning goals, few have applied them to online education contexts or have explored how learners' perceptions of the value of knowing learning goals affects their learning. Accordingly, the present study defined PVKLG in online courses as students actively strive to engage in online learning during the COVID-19 pandemic lockdown.

\section{Learning Engagement}

Learning engagement is commonly considered as a predictor of academic performance (Froiland \& Oros, 2014). Fredricks and Paris (2004) identified student engagement as comprising the three dimensions of behavioral engagement, emotional engagement, and cognitive engagement. In online learning contexts, behavioral engagement refers to those activities related to the learning itself and which cause issues during learning processes. In comparison, cognitive engagement refers to the extent of learners' cognitive efforts to acquire complex information and to deal with online learning issues, while emotional engagement refers to the degree of learners' positive feelings toward their instructors, peers, and/or the online learning itself (Jung \& Lee, 2018).

Learning engagement for distance learning contexts has attracted considerable attention because of its psychological mechanisms (Geng et al., 2020). However, online learning has been criticized because of its weak engagement practices, which hinder interactivity and the generation of personalized feedback (Chapman et al., 2016). Students have to practice autonomous learning by themselves during online learning, but how they really engage in online learning during the COVID-19 lockdown has not been extensively studied; thus, the present study focused on students' online learning engagement during the COVID19 pandemic.

\section{Hypotheses and Research Model}

\section{Hypotheses}

\section{SDL Attitude and Approach Relevant to PVKLG}

SDL is an individual characteristic influencing students to become aware that they are individually responsible for their own learning. They tend to become clear about their learning needs and are willing to set their own learning goals (Fatemeh et al., 2016; Karatas \& Arpaci, 2021). A previous study pointed out that improving learning attitude and learning approaches is essential to online learning (Shahrouri, 2016). Moreover, there is overwhelming research evidence showing that SDL is crucial to PVKLG (e.g., Froiland \& Worrell, 2016; Song, 2021); however, few studies have investigated whether students' SDL is related to their PVKLG; thus, how the two types of SDL are related to PVKLG was hypothesized as follows:

H1 SDL attitude is positively related to PVKLG.

H2 SDL approach is positively related to PVKLG.

\section{PVKLG Relevant to Learning Engagement}

Knowing the learning goals can enhance learners' motivation and then in turn increase their behavioral engagement. Kizilcec et al. (2017) found that knowing the learning goals can predict learners' engagement in the pursuit of personal course goals. Learners with stronger PVKLG are more likely to revise their course materials. Another study pointed out that achieving learning goals signify students' perceptions that the learning goals will orient their engagement in pre-class learning (Sun \& Xie, 2020). Research has highlighted that learning goals lead to higher cognitive engagement (Froiland \& Worrell, 2016) and students will decrease cognitive engagement if there are unclear learning goals (Lane et al., 2021). However, few studies have identified whether the three types of learning engagement can be predicted by PVKLG. Thus, how students' PVKLG in online learning tasks may influence their three types of engagement was hypothesized as follows:

H3 PVKLG is positively related to behavioral engagement. 
$\mathrm{H} 4$ PVKLG is positively related to emotional engagement.

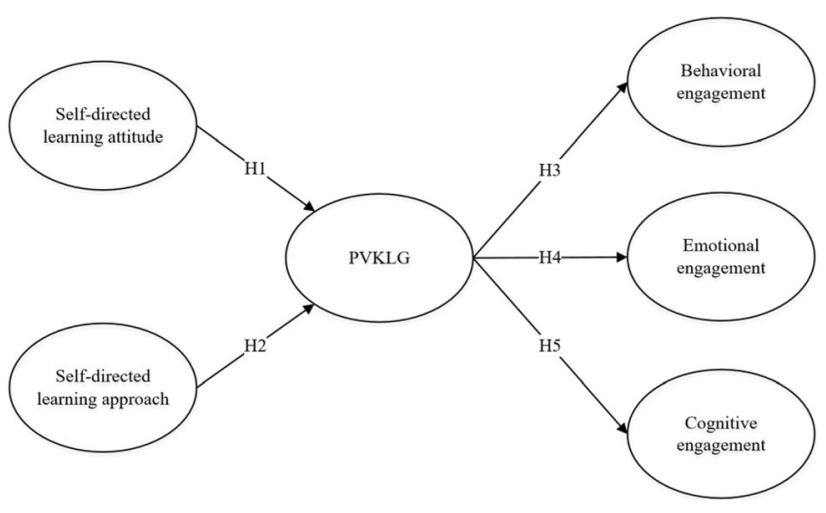

H5 PVKLG is positively related to cognitive engagement.

\section{SDL Attitude and Approach Relevant to Learning Engagement}

Learning persistence is one type of SDL attitude, which relates to students' continued engagement with courses, and shows the extent to which learners meet the learning goals that are provided by teachers as learning opportunities for online learning (Jung \& Lee, 2018). Moreover, in online learning environments, SDL learners will evaluate cause and effect that affects their attitude and motivation to engage more to meet their learning achievement needs. Reschly and Christenson (2012) posited that the student engagement framework is mediated by students' perceived learning value in relation to their belief in SDL. However, in the context of the pandemic lockdown, how the two types of SDL related to the three types of online learning engagement mediated by students' PVKLG was hypothesized as follows:

H6 SDL attitude and approach are related to the three types of learning engagement mediated by PVKLG.

\section{Research Model}

Expectancies for success in a job are related to individuals' beliefs about how well they are able to complete tasks by themselves (Eccles \& Wigfield, 2002). According to SEVT, students' engagement in tasks is driven by their task-specific beliefs, and more specifically, the expectancy they have that they can succeed in performing certain tasks, and the value they attach to those tasks. Drawing on SEVT, how SDL attitude and approach related to PVKLG and the three types of learning engagement related to online learning during COVID-19 are hypothesized in the following research model (see Fig. 1). Particularly, the direct effects are depicted as Hypotheses $\mathrm{H} 1-\mathrm{H} 5$, whereas the indirect effect, which means the relationships between the two types of SDL and the three types of engagement mediated by PVKLG, is stated as H6.

\section{Methods}

\section{Procedure and Participants}

This study applied snowball sampling and targeted students in higher education. The instruments to measure different variables were made into electronic questionnaires, which

Fig. 1 The research model

were opened for a week in June 2020. Participants were selected from university student associations in Beijing. All participants were informed of the objectives and the confidentiality of the study, and they could quit the investigation at any time. They were also informed that there were no correct or incorrect answers to the items.

A total of 535 students submitted their responses, from which the invalid responses were deleted (i.e., those responses with the same option for all items), leaving 497 valid data for analysis. In terms of gender, 30\% (149) were male and $70 \%$ (348) were female; as for school level, 385 $(77.5 \%)$ were undergraduate students and $112(22.5 \%)$ were graduate students. The participants were aged between 17 and 55 years $(M=22.14, S D=4.61)$.

\section{Instruments}

The questionnaire items were adapted and modified from previous theories and researchers, and a 5-point scale, from 1 , meaning strongly disagree to 5, meaning strongly agree, was adopted. The reliability and validity were tested after data collection and were then subjected to confirmatory factor analysis (CFA).

- SDL Measuring SDL can offer an understanding of individuals' attitudes toward online learning and provide further insights into how individuals use approaches to learn from online environments (Beach, 2017). Adapted from this assertion, the present study designed five items for SDL attitude and five for SDL approach; see Table 1 for sample items.

- PVKLG Johnson and Payne's (1985) behavioral decision theory can explain individuals' choices in a range of decision-making situations, as well as the cognitive trade-offs between the efforts made and the usefulness of the resulting decision (Yang et al., 2018). In the present study, PVKLG represents this relationship. Accordingly, seven items were designed to explore participants' PVKLG. Table 1 shows sample items. 
Table 1 Sample items of each construct

\begin{tabular}{ll}
\hline Dimension & Item \\
\hline SDL attitude & If it is something I am interested in, I will try to understand it by myself no matter how difficult it is \\
When a new concept or thing comes along, I like to explore it on my own \\
SDL approach & $\begin{array}{l}\text { I regularly surf the Internet for new information about my studies } \\
\text { When there are difficulties in using the learning system, I will find the best way to solve it by myself }\end{array}$ \\
PVKLG & It is important for me to know what new concepts I can learn in this course \\
Behavioral engagement & $\begin{array}{l}\text { It is important for me to know what strategies I can use to learn more effectively in this course } \\
\text { When I study online, I don't ask for leave without a reason }\end{array}$ \\
Cognitive engagement & When I study online, I will finish all my homework \\
Emotional engagement & When I make mistakes in my online study, I will pay attention not to do it again \\
& When studying online, I take notes with well-structured headings \\
& When I study online, I like to discuss with my classmates \\
& When studying online, I like to learn the extracurricular knowledge that the teachers provide
\end{tabular}

- Engagement Behavioral engagement, cognitive engagement, and emotional engagement were adopted and modified from the works of Jung and Lee (2018). Accordingly, the present study designed six items for behavioral engagement, six for cognitive engagement, and six for emotional engagement. Sample items are shown in Table 1.

\section{Data Analysis}

There were two phases of data analysis in this study, namely CFA and structural equation modeling (SEM). CFA examined the construct validity of the questionnaires and clarified the model fit, while SEM was used to explore the structure relationships existing between SDL, PVKLG, and online learning engagement. AMOS is commonly used software to perform SEM, because it can be used to verify the path relationships between potential variables. Thus, the model fit and path analysis were performed with AMOS 21.0 with maximum likelihood estimation.

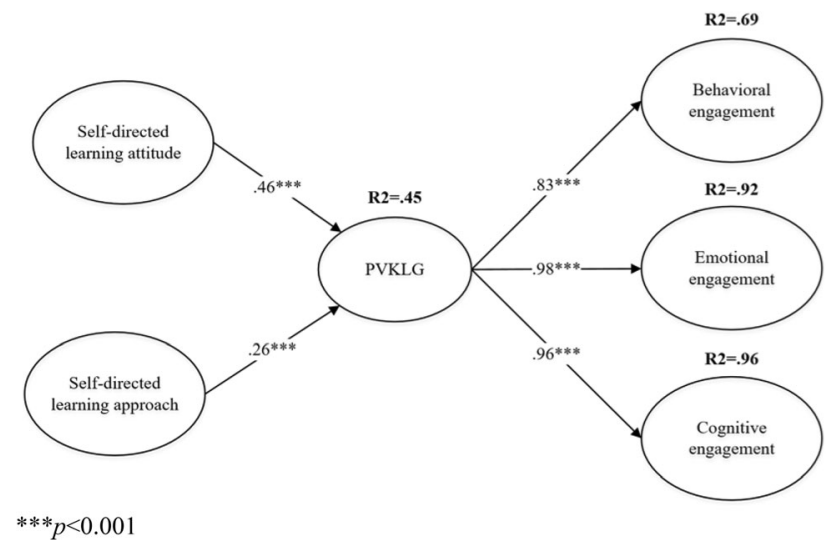

Fig. 2 Verification of the research model $(* * * p<0.001)$

\section{Results}

\section{Questionnaire Item Analysis}

This study conducted internal and external validity analyses to reduce the number of items in each construct. Firstly, items with a factor loading (FL) of less than 0.5 were deleted and then we deleted the highest residual value of each construct until the threshold of first-order CFA was met, as suggested by Hair et al. (2019). Then, we conducted independent $t$ tests with the extreme value method to explore the $t$ value of each construct. All $t$ values surpassed 3 and were significant. Table 2 shows the results of each construct, which indicates that there was good external validity for each item.

\section{Reliability and Validity Analyses}

To test the reliability and validity of the instrument, the internal consistency of constructs was examined by Cronbach's alpha, and the external consistency of constructs was examined by composite reliability (CR). Table 2 shows that all alpha values ranged from 0.76 to 0.90 (above 0.50 ), and the overall alpha was 0.95 . Additionally, all CR values in this study surpassed the threshold value of 0.7 (ranging from 0.74 to 0.90 ). Both internal and external consistencies were acceptable according to Hair et al.'s (2019) recommendations.

To test the convergent validity of the constructs, the average variance extracted (AVE) values and the FL of all constructs were tested. Table 3 shows that all AVE values exceeded 0.50 (ranging from 0.50 to 0.67 ) and all FL values were larger than 0.5 (see Table 2), which means that the convergent validity of the construct can be considered adequate (Hair et al., 2019). To test the discriminant validity between constructs, it is necessary to examine 
whether the square root of the AVE is larger than the absolute value of the Pearson correlation coefficient between two constructs (Cheung \& Wang, 2017). The results in Table 4 show that each construct has discriminative validity.

\section{Model Fit Analysis}

Researchers should consider absolute fit measures, incremental fit measures, and parsimonious fit measures to ensure a good model. The results show that $\chi^{2} / \mathrm{df}=2.78$, GFI $=0.90$, AGFI $=0.87$, and RMSEA $=0.06$. The other values for the indicators of model fit are as follows: $\mathrm{NFI}=0.91, \mathrm{TLI}=0.93, \mathrm{CFI}=0.94$, and $\mathrm{IFI}=0.94 ;$ all were larger than 0.90 . Additionally, PNFI $=0.81$ and
PGFI $=0.73$. These indicators show satisfactory fitness of the final model (Hair et al., 2019).

\section{Path Analysis}

Path coefficients of the final model are shown in Table 5. SDL attitude was significantly correlated to PVKLG $(\beta=0.46, t=6.24 * * *)$, SDL approach was significantly correlated to PVKLG $(\beta=0.26, t=3.62 * * *)$, PVKLG was significantly correlated to behavioral engagement ( $\left.\beta=0.83, t=12.21^{* * *}\right)$, PVKLG was significantly correlated to cognitive engagement $\left(\beta=0.96, t=16.33^{* * *}\right)$, and PVKLG was significantly correlated to emotional engagement $\left(\beta=0.98, t=12.67^{* * *}\right)$. As reported in Table 6 , the indirect effect of SDL attitude on behavioral

Table 2 Item analysis

\begin{tabular}{|c|c|c|c|c|c|}
\hline & \multicolumn{4}{|c|}{ Internal validity } & \multirow{2}{*}{$\begin{array}{l}\text { External validity } \\
t \text { value }\end{array}$} \\
\hline & $\begin{array}{c}\chi^{2} / \mathrm{df} \\
<5\end{array}$ & $\begin{array}{l}\text { GFI } \\
>0.8\end{array}$ & $\begin{array}{l}\text { AGFI } \\
>0.8\end{array}$ & $\begin{array}{c}\text { RMSEA } \\
<0.08\end{array}$ & \\
\hline SDL attitude & 0.27 & 0.92 & 0.99 & 0.00 & $18.95-22.51$ \\
\hline SDL approach & - & 0.90 & - & - & $20.01-24.24$ \\
\hline PVKLG & - & 0.93 & - & - & $15.89-21.96$ \\
\hline Behavioral engagement & 2.33 & 0.92 & 0.97 & 0.05 & $17.55-27.95$ \\
\hline Emotional engagement & 3.63 & 0.96 & 0.96 & 0.07 & $14.17-20.99$ \\
\hline Cognitive engagement & 2.72 & 0.95 & 0.97 & 0.06 & $18.47-21.28$ \\
\hline
\end{tabular}

Table 3 Reliability and validity analysis

\begin{tabular}{lllllr}
\hline Items & Mean & SD & CR & Cronbach's $\alpha$ & AVE \\
& - & - & $>0.7$ & $\begin{array}{c}\text { FL } \\
>0.7\end{array}$ & 0.5 \\
\hline SDL attitude & 3.57 & 0.74 & 0.84 & 0.83 & 0.56 \\
SDL approach & 3.24 & 0.92 & 0.76 & 0.76 & 0.75 \\
PVKLG & 3.87 & 0.75 & 0.74 & 0.85 & 0.71 \\
Behavioral engagement & 3.96 & 0.80 & 0.90 & 0.90 & 0.70 \\
Emotional engagement & 3.93 & 0.73 & 0.89 & 0.89 & 0.65 \\
Cognitive engagement & 3.79 & 0.69 & 0.83 & 0.83 & 0.67 \\
\hline
\end{tabular}

Table 4 Construct discriminant validity analysis

\begin{tabular}{llllll}
\hline & 1 & 2 & 3 & 4 & 5 \\
\hline SDL attitude & $\mathbf{0 . 7 5}$ & & & & \\
SDL approach & 0.55 & $\mathbf{0 . 7 1}$ & & & \\
PVKLG & 0.53 & 0.45 & $\mathbf{0 . 7 0}$ & 0.61 & $\mathbf{0 . 8 1}$ \\
Behavioral engagement & 0.44 & 0.41 & 0.68 & 0.74 & $\mathbf{0 . 8 2}$ \\
Emotional engagement & 0.50 & 0.43 & 0.69 & 0.73 & 0.81 \\
Cognitive engagement & 0.52 & 0.45 & $\mathbf{0 . 7 1}$ \\
\hline
\end{tabular}


Table 5 Path analysis

\begin{tabular}{llllc}
\hline Path & Standardized coefficient $(\beta)$ & SE & $t$ value & Supported? \\
\hline SDL attitude $\rightarrow$ PVKLG & 0.46 & 0.06 & $6.24 * * *$ & Yes \\
SDL approach $\rightarrow$ PVKLG & 0.26 & 0.05 & $3.61^{* * *}$ & Yes \\
PVKLG $\rightarrow$ Behavioral engagement & 0.83 & 0.07 & $12.21^{* * *}$ & Yes \\
PVKLG $\rightarrow$ Cognitive engagement & 0.96 & 0.07 & $16.33^{* * *}$ & Yes \\
PVKLG $\rightarrow$ Emotional engagement & 0.98 & 0.08 & $12.67^{* * *}$ & Yes \\
\hline
\end{tabular}

$* * * p<0.001$

Table 6 Indirect effect analysis

\begin{tabular}{|c|c|c|c|c|}
\hline & \multicolumn{2}{|c|}{ SDL attitude } & \multicolumn{2}{|c|}{ SDL approach } \\
\hline & $\beta$ & $95 \% \mathrm{CI}$ & $\beta$ & $95 \% \mathrm{CI}$ \\
\hline Behavioral engagement & $0.28 * *$ & {$[0.22,0.84]$} & 0.02 & {$[0.02,0.54]$} \\
\hline Cognitive engagement & $0.20 * *$ & {$[0.28,0.97]$} & 0.06 & {$[0.02,0.62]$} \\
\hline Emotional engagement & $0.21 * *$ & {$[0.24,0.93]$} & 0.12 & {$[0.02,0.60]$} \\
\hline
\end{tabular}

$* * p<0.01$

engagement is $\beta=0.28$, the indirect effect of SDL attitude on cognitive engagement is $\beta=0.20$, the indirect effect of SDL attitude on emotional engagement is $\beta=0.21$, the indirect effect of SDL approach on behavioral engagement is $\beta=0.02$, the indirect effect of SDL approach on cognitive engagement is $\beta=0.06$, and the indirect effect of SDL approach on emotional engagement is $\beta=0.12$. Additionally, each 95\% confidence interval (CI) did not include zero, which means that the indirect effect existed in this research model, and there is a mediation effect for each path (see Fig. 2).

\section{Discussion}

Based on SEVT, this study explored whether different aspects of students' SDL in online learning situations could significantly predict their learning engagement with PVKLG as a mediator. Accordingly, this study explored those correlations between SDL attitude and approach, PVKLG, as well as three dimensions of learning engagement, and found that all constructs were positively related. The detailed results of this study are further illustrated below.

In examining $\mathrm{H} 1$, the result of the present study showed that participants' SDL attitude positively related to PVKLG. When students have a positive attitude towards SDL, they need a relatively clear learning goal (Ames \& Archer, 1988). This result is supported by the study of Jufrida et al. (2019) which argued that students have negative attitudes toward physics, so they do not consider learning goals in advance as having task or attainment value. In line with this, H1 was positively supported.

For hypothesis $\mathrm{H} 2$, this study revealed that participants' SDL approach positively related to PVKLG. With the SDL approach, learners tend to effectively plan for their learning; meanwhile, they may also change learning strategies according to their targets, until they achieve their goals (Littlejohn et al., 2016). Kizilcec et al. (2017) found that online learners who have their own learning approaches and participate in the process of setting learning goals are more likely to achieve their goals. Consistent with these assertions, $\mathrm{H} 2$ was positively supported.

To test hypothesis H3, this study shows that participants' PVKLG was positively related to their behavioral engagement. When students emphasize their learning goals, they will choose the strategies needed to achieve goals; they are then more likely to have positive behavioral engagement (Chang et al., 2018; Daniels et al., 2021). The result of this study is consistent with the study of Gonida et al. (2009) which suggested that the perceived value of learning goals and having a strong learning goal orientation can positively predict students' behavioral engagement. Accordingly, H3 was positively supported.

The result of $\mathrm{H} 4$ testing indicated that the participants' PVKLG was positively related to their emotional engagement. After setting learning goals, students tend to show positive emotions and are willing to participate in their learning processes, because they are able to help them achieve their learning goals (Mih et al., 2015). Cho (2014) found that perceiving the value of learning goals can promote online learners' emotional engagement. Conclusively, H4 was positively supported. 
In examining $\mathrm{H} 5$, the results reported that participants' PVKLG positively related to their cognitive engagement. Cognitive engagement is one of the important factors used to evaluate the quality of learners' online learning (Shukor et al., 2014). Previous studies have demonstrated that if learners emphasize the learning goals, their efforts to achieve them can stimulate their deep cognitive engagement in the learning process (Daniels et al, 2021; Lee \& Koszalka, 2016). Consistent with these studies, H5 was positively supported.

In testing H6, this study showed that SDL attitude and approach positively related to learning engagement mediated by PVKLG. Voss and Richards (2016) noticed that when learners positively engage in learning, their learning process becomes more self-directed. With a high level of SDL, students are often willing to devote themselves to learning and even more, want to know what knowledge or skills they can acquire from the course (Jung \& Lee, 2018). Additionally, this study viewed PVKLG as a mediator variable; when learners had a high level of PVKLG, they would regulate their learning approaches according to the learning goals to promote their engagement in learning. Conclusively, H6 was positively supported.

Kirk-Johnson et al. (2019) emphasized that understanding the attitude and processes behind learners' decisions to engage more in learning is essential when conducting online learning courses. Based on SEVT, the present study aimed to explore the direct relationships between the approach and attitude of SDL and PVKLG, and PVKLG for predicting students' online learning engagement, and indirect relationships between two types of SDL and three types of online learning engagement during COVID-19. In conclusion, the path in the research model was verified and indicated that the direct effects and indirect effects between SDL attitude and approach, PVKLG, and the three types of learning engagement were positively supported through SEM.

\section{Conclusion}

Learners need to know what goals they want to achieve before they decide in what order to study, which indicates that knowing the learning goals plays an important role in learners' efforts in online learning; that is, there is no online learning without autonomy and there is no autonomy without knowing the learning goals (Hein et al., 2020). To understand the role of knowing learning goals, this study adopted PVKLG as the mediating variable related to the SEVT to verify the correlates between the two types of SDL and the three types of learning engagement. The results indicate that PVKLG is a critical mediating factor influencing online learning engagement.
Learners who not only know the learning goals but also perceive that they know the learning goals are more likely to engage in online learning.

\section{Implications and Recommendations}

Compared to previous studies, the findings of this study contribute to the current research by exploring the relationship between SDL and engagement mediated by PVKLG, guided by SEVT. The present study is the first attempt to subdivide SDL into SDL attitude and SDL approach; of course, this will advance our understanding in future SDL research. Furthermore, this study implies that letting students realize the importance of perceiving the value of knowing learning goals can help them achieve the teaching goals during the COVID-19 lockdown. Accordingly, it is suggested that teachers should inform students' PVKLG before beginning online teaching.

One recommendation is made according to SVET: informing learners of course goals and clarifying the goals can help cultivate their value perception of the learning goals. Instructors should consider how to enhance students' awareness of the learning goals, in particular, when students need to engage in distance learning during pandemic periods.

\section{Limitations and Future Study}

There are some limitations to this study that should be noted. First, the subjects might not have been actively participating in online courses at the time they completed the questionnaires, and their previous online learning experience might not have been so clear. To address this issue, future studies may use purposive sampling and focus on students in particular online courses to test the relationships among the constructs in this study. Second, this study indicates that PVKLG plays an important mediating role between SDL and online learning engagement; therefore, PVKLG may also play a critical role in mediating SDL and learning engagement in face-to-face learning. Future studies may examine the role of PVKLG in face-toface contexts and compare it with online contexts.

Funding This work was supported by the International Joint Research Project of Faculty of Education, Beijing Normal University (Grant No. ICER201902). 


\section{References}

Ames, C., \& Archer, J. (1988). Achievement goals in the classroom: Students' learning strategies and motivation processes. Journal of Educational Psychology, 80(3), 260-267.

Arievitch, I. M. (2020). The vision of developmental teaching and learning and Bloom's Taxonomy of educational objectives. Learning, Culture and Social Interaction, 25, 1-6.

Beach, P. (2017). Self-directed online learning: A theoretical model for understanding elementary teachers' online learning experiences. Teaching and Teacher Education, 61, 60-72.

Biggs, J., Kember, D., \& Leung, D. (2001). The Revised Two Factor Study Process Questionnaire: R-SPQ-2F. British Journal of Educational Psychology, 71, 133-149.

Caffarella, R. (1993). Self-directed learning. New Directions for Adult and Continuing Education, 57, 25-35.

Chang, C. C., Liang, C., Chou, P. N., \& Liao, Y. M. (2018). Using e-portfolio for learning goal setting to facilitate self-regulated learning of high school students. Behaviour \& Information Technology, 37(12), 1237-1251.

Chapman, S. A., Goodman, S., Jawitz, J., \& Deacon, A. (2016). A strategy for monitoring and evaluating massive open online courses. Evaluation and Program Planning, 57, 55-63.

Cheung, G. W., \& Wang, C. (2017). Methodological artifacts in moderated multiple regression: A latent moderated SEM solution. Academy of Management Annual Meeting Proceedings, 2017(1), 11149.

Cho, C. Y. (2014). Instructor scaffolding for interaction and students' academic engagement in online learning: Mediating role of perceived online class goal structures. The Internet and Higher Education, 21, 25-30.

Daniels, L. M., Goegan, L. D., \& Parker, P. C. (2021). The impact of COVID-19 triggered changes to instruction and assessment on university students' self-reported motivation, engagement and perceptions. Social Psychology of Education, 24(1), 299-318.

de Moura, V. F., de Souza, C. A., \& Viana, A. B. N. (2021). The use of Massive Open Online Courses (MOOCs) in blended learning courses and the functional value perceived by students. Computers \& Education, 161, 104077.

Dolmans, D. H., Loyens, S. M., Marcq, H., \& Gijbels, D. (2016). Deep and surface learning in problem-based learning: A review of the literature. Advances in Health Sciences Education, 21(5), $1087-1112$.

Dweck, C. (1986). Motivational processes affecting learning. American Psychologist, 41(10), 1040-1048.

Dwivedi, A., Dwivedi, P., Bobek, S., \& Sternad Zabukovsek, S. (2019). Factors affecting students' engagement with online content in blended learning. Kybernetes, 48(7), 1500-1515.

Eccles, J. S. (2009). Who am I and what am I going to do with my life? Personal and collective identities as motivators of action. Educational Psychologist, 44(2), 78-89.

Eccles, J. S., \& Wigfield, A. (2002). Motivational beliefs, values, and goals. Annual Review of Psychology, 53, 109-132.

Eccles, J. S., \& Wigfield, A. (2020). From expectancy-value theory to situated expectancy-value theory: A developmental, social cognitive, and sociocultural perspective on motivation. Contemporary Educational Psychology, 61, 101859.

Fatemeh, H., Mohammad, R. A., \& Ali, M. M. (2016). On the effect of goal setting on self-directed learning, achievement motivation, and academic achievement among students. Modern Applied Science, 11(1), 37-47.

Fong, C. J., Kremer, K. P., Cox, C. H. T., \& Lawson, C. A. (2021). Expectancy-value profiles in math and science: A personcentered approach to cross-domain motivation with academic and STEM-related outcomes. Contemporary Educational Psychology, 65, 1-27.

Fredricks, J. A., \& Paris, B. A. H. (2004). School engagement: Potential of the concept, state of the evidence. Review of Educational Research, 74(1), 59-109.

Froiland, J. M., \& Oros, E. (2014). Intrinsic motivation, perceived competence and classroom engagement as longitudinal predictors of adolescent reading achievement. Educational Psychology, 34(2), 119-132.

Froiland, J. M., \& Worrell, F. C. (2016). Intrinsic motivation, learning goals, engagement, and achievement in a diverse high school. Psychology in the Schools, 53(3), 321-336.

Garrison, D. R. (1997). Self-directed learning: Toward a comprehensive model. Adult Education Quarterly, 48(1), 18-33.

Geng, L., Zheng, Q., Zhong, X., \& Li, L. (2020). Longitudinal relations between students' engagement and their perceived relationships with teachers and peers in a Chinese secondary school. The Asia-Pacific Education Researcher, 29(2), 171-181.

Gonida, E. N., Voulala, K., \& Kiosseoglou, G. (2009). Students' achievement goal orientations and their behavioral and emotional engagement: Co-examining the role of perceived school goal structures and parent goals during adolescence. Learning and Individual Differences, 19(1), 53-60.

Guo, J., Marsh, H. W., Parker, P. D., Morin, A. J. S., \& Dicke, T. (2017). Extending expectancy-value theory predictions of achievement and aspirations in science: Dimensional comparison processes and expectancy-by-value interactions. Learning and Instruction, 49, 81-91.

Hair, J. F., Black, W. C., Babin, B. J., Anderson, R. E., \& Tatham, R. L. (2019). Multivariate data analysis (8th ed.). Cengage.

Hein, J., Daumiller, M., Janke, S., Dresel, M., \& Dickhäuser, O. (2019). How learning time mediates the impact of university Scholars' learning goals on professional learning in research and teaching. Learning and Individual Differences, 72, 15-25.

Hein, J., Janke, S., Daumiller, M., Dresel, M., \& Dickhauser, O. (2020). No learning without autonomy? Moderators of the association between university instructors' learning goals and learning time in the teaching related learning process. Learning and Individual Differences, 83-84, 101937.

Johnson, E. J., \& Payne, J. W. (1985). Effort and accuracy in choice. Management Science, 31(4), 395-414.

Jufrida, J., Kurniawan, W., Astalini, A., Darmaji, D., \& Maya, W. A. (2019). Students' attitude and motivation in mathematical physics. International Journal of Evaluation and Research in Education, 8(3), 401-408.

Jung, Y., \& Lee, J. (2018). Learning engagement and persistence in massive open online courses (MOOCS). Computers \& Education, 122, 9-22.

Karatas, K., \& Arpaci, I. (2021). The role of self-directed learning, metacognition, and 21 st century skills predicting the readiness for online learning. Contemporary Educational Technology, 13(3), ep300.

Kirk-Johnson, A., Galla, B. M., \& Fraundorf, S. H. (2019). Perceiving effort as poor learning: The misinterpreted-effort hypothesis of how experienced effort and perceived learning relate to study strategy choice. Cognitive Psychology, 115, 1-31.

Kizilcec, R. F., Perez-Sanagustín, M., \& Maldonado, J. J. (2017). Self-regulated learning strategies predict learner behavior and goal attainment in Massive Open Online Courses. Computers \& Education, 104, 18-33.

Lane, S., Hoang, J. G., Leighton, J. P., \& Rissanen, A. (2021). Engagement and Satisfaction: Mixed-method analysis of blended learning in the sciences. Canadian Journal of Science, Mathematics and Technology Education, 21(1), 100-122. 
LaTour, K. A., \& Noel, H. N. (2021). Self-directed learning online: An opportunity to binge. Journal of Marketing Education. https://doi.org/10.1177/0273475320987295

Lee, S., \& Koszalka, T. A. (2016). Course-level implementation of first principles, goal orientations, and cognitive engagement: A multilevel mediation model. Asia Pacific Education Review, 17(2), 365-375.

Littlejohn, A., Hood, N., Milligan, C., \& Mustain, P. (2016). Learning in MOOCs: Motivations and self-regulated learning in MOOCs. The Internet and Higher Education, 29, 40-48.

Loh, E. K. Y. (2019). What we know about expectancy-value theory, and how it helps to design a sustained motivating learning environment. System, 86, 102119.

Mih, V., Mih, C., \& Drago, V. (2015). Achievement goals and behavioral and emotional engagement as precursors of academic adjusting. Procedia-Social and Behavioral Sciences, 209, 329-336.

Pengpai News. (2020). Online Teaching in the Context of the COVID-19: Problems and Countermeasures. Retrieved from https://www.sohu.com/a/374995866_260616/.

Reschly, A. L., \& Christenson, S. L. (2012). Jingle, jangle, and conceptual haziness: Evolution and future directions of the engagement construct. In S. L. Christenson, A. L. Reschly, \& C. Wylie (Eds.), Handbook of research on student engagement (pp. 3-20). Springer.

Schmidt, J. A., Kafkas, S. S., Maier, K. S., Shumow, L., \& KackarCam, H. Z. (2019). Why are we learning this? Using mixed methods to understand teachers' relevance statements and how they shape middle school students' perceptions of science utility. Contemporary Educational Psychology, 57, 9-31.

Seetee, N., Chi, C., Dhir, A., \& Chen, S. (2021). Validation of the science, mathematics, and English task value scales based on longitudinal data. International Journal of Science \& Mathematics Education, 19(3), 1-18.

Seijts, G. H., Latham, G. P., \& Woodwark, M. (2013). Learning goals: A qualitative and quantitative review. In E. A. Locke \& G. P. Latham (Eds.), New development in goal setting and task performance. Routledge.

Shahrouri, E. (2016). The impact of Garrison's Model of self-directed learning on improving academic self-concept for undergraduate students. International Journal of Education, Learning and Development, 4(10), 36-45.

Shukor, N. A., Tasir, Z., Henny, V. D. M., \& Harun, J. (2014). A predictive model to evaluate students' cognitive engagement in online learning. Procedia-Social and Behavioral Sciences, 116, 4844-4853.

Song, B. K. (2021). E-portfolio implementation: Examining learners' perception of usefulness, self-directed learning process and value of learning. Australasian Journal of Educational Technology, $37(1), 68-81$.

Song, L., \& Hill, J. R. (2007). A conceptual model for understanding self-directed learning in online environments. Journal of Interactive Online Learning, 6(1), 27-42.

Stetsenko, A. (2017). The transformative mind: Expanding Vygotsky's approach to development and education. Cambridge University Press.

Sun, Z., \& Xie, K. (2020). How do students prepare in the pre-class setting of a flipped undergraduate math course? A latent profile analysis of learning behavior and the impact of achievement goals. The Internet and Higher Education, 46, 1-12.

Torshizi, M. D., \& Bahraman, M. (2019). I explain, therefore I learn: Improving students' assessment literacy and deep learning by teaching. Studies in Educational Evaluation, 61, 66-73.

Voss, R., \& Richards, T. (2016). Promoting students' self-directed learning ability through teaching mathematics for social justice. Journal of Education and Practice, 7(26), 77-82.

Wigfield, A., \& Eccles, J. S. (1992). The development of achievement task values: A theoretical analysis. Developmental Review, 12, 265-310.

Wigfield, A., \& Eccles, J. S. (2000). Expectancy-value theory of achievement motivation. Contemporary Education, 25(1), $68-81$.

Wigfield, A., Tonks, S., \& Klauda, S. T. (2009). Expectancy-value theory. In K. R. Wentzel \& A. Wigfield (Eds.), Handbook of motivation at school (2nd ed., pp. 55-75). Routledge.

Yang, S., Jiang, H., Yao, J., Chen, Y., \& Wei, J. (2018). Perceived values on mobile GMS continuance: A perspective from perceived integration and interactivity. Computers in Human Behavior, 89(12), 16-26.

Zheng, B., Lin, C. H., \& Kwon, J. B. (2020). The impact of learner-, instructor-, and course-level factors on online learning. Computers \& Education, 150, 1-11.

Zhu, M. (2021). Enhancing MOOC learners' skills for self-directed learning. Distance Education, 42(3), 441-460.

Publisher's Note Springer Nature remains neutral with regard to jurisdictional claims in published maps and institutional affiliations. 